\title{
Facile Synthesis of Ni-Co Double Hydroxide on Carbonized Cotton Cloth for High Performance Supercapacitor
}

\author{
Yanni Shen ${ }^{1}$, Xueli Miao ${ }^{1}$, Dandan Song ${ }^{1}$, Yanting Li $^{1}$, Yuning $Q u^{1}$, Jianguo Yu ${ }^{1}$, Jiajun Tang ${ }^{2}$, Hao \\ Qin $^{1}$, Lili wang ${ }^{1, *}$, Jiahao Ren ${ }^{l}$, Bing Wang ${ }^{1, *}$ \\ ${ }^{1}$ School of Environment and Chemical Engineering, State Key Laboratory of Separation Membranes \\ and Membrane Processes, Tianjin Polytechnic University, 399 Binshui West Road, Tianjin 300387, P. \\ R. China \\ ${ }^{2}$ School of Materials Science and Engineering and Tianjin Key Laboratory of Fiber, Tianjin \\ Polytechnic University, Tianjin 300387, China \\ *E-mail: wanglili@tjpu.edu.cnbingwang@tjpu.edu.cn
}

doi: $10.20964 / 2019.03 .30$

Received: 20 November 2018/ Accepted: 12 January 2019 / Published: 7 February 2019

A facile and novel one-step hydrothermalmethod was provided for the preparation of Ni-Co double hydroxides (NC-DH), which was directly grown on carbonized cotton cloth (CCC) and used as advanced binder-free electrodes for supercapacitors. The effect of different concentration of $\mathrm{Ni}^{2+}$ and $\mathrm{Co}^{2+}$ in the intial reactant $(\mathrm{C}-\mathrm{Ni}-\mathrm{x}-\mathrm{Co}-\mathrm{y})$ on microstructure and electrochemical performance were studied. The results showed that flake-like structure grown uniformly under an appropriate concentration, which was benefit to improve the electrochemical performance. The electrochemical tests revealed that the C-Ni-4-Co-8 electrode displayed the maximum specific capacitance of $4.19 \mathrm{~F}$ $\mathrm{cm}^{-2}$ when the current density was $5 \mathrm{~mA} \mathrm{~cm}$ and excellent rate capability maintained at $3.05 \mathrm{~F} \mathrm{~cm}^{-2}$ even at the high current density of $80 \mathrm{~mA} \mathrm{~cm}{ }^{-2}$. The electrodes of Ni-Co double hydroxides anchored on flexible conductive substrates with excellent electrochemical properties could be obtained by costeffective method, which could be ascribed as a highly promising potential electrode material for energy storage devices.

Keywords: Ni-Co double hydroxide, carbonized cotton cloth, hydrothermal method, supercapacitor.

\section{$\underline{\text { FULL TEXT }}$}

(C) 2019 The Authors. Published by ESG (www.electrochemsci.org). This article is an open access article distributed under the terms and conditions of the Creative Commons Attribution license (http://creativecommons.org/licenses/by/4.0/). 